\title{
Cross-national clinical and functional remission rates: Worldwide Schizophrenia Outpatient Health Outcomes (W-SOHO) study ${ }^{\dagger}$
}

Josep Maria Haro, Diego Novick, Jordan Bertsch, Jamie Karagianis, Martin Dossenbach and Peter B. Jones

\section{Background}

Evidence suggests that schizophrenia may have a better outcome for individuals living in low- and middle-income countries compared with affluent settings.

\begin{abstract}
Aims
To determine the frequency of symptom and functional remission in out-patients with schizophrenia in different
\end{abstract} regions of the world.

\begin{abstract}
Method
Using data from the Worldwide-Schizophrenia Outpatient Health Outcomes (W-SOHO) study we measured clinical and functional remission in out-patients with schizophrenia in different regions of the world, and examined sociodemographic and clinical factors associated with these outcomes. The 11078 participants analysed from 37 participating countries were grouped into 6 regions: South Europe, North Europe, Central and Eastern Europe, Latin America, North Africa and Middle East, and East Asia.
\end{abstract}

\section{Results}

In total, 66.1\% achieved clinical remission during the 3-year follow-up (range: $60.1 \%$ in North Europe to $84.4 \%$ in East Asia) and $25.4 \%$ achieved functional remission (range: $17.8 \%$ in North Africa and Middle East to $35.0 \%$ in North Europe). Regional differences were not explained by participants' clinical characteristics. Baseline social functioning, being female and previously untreated were consistent predictors of remission across regions.

\section{Conclusions}

Clinical outcomes of schizophrenia seem to be worse in Europe compared with other regions. However, functional remission follows a different pattern.

\section{Declaration of interest}

J.M.H is a consultant for Lilly and Lundbeck and has received honoraria from AstraZeneca, Lundbeck and Lilly. D.N., J.K. and M.D. are Lilly employees. J.B. was a statistical consultant for the $\mathrm{SOHO}$ study. P.B.J. received grant support from GlaxoSmithKline and honoraria from Bristol-Myers Squibb and Otsuka for lecturing.
The International Pilot Study of Schizophrenia (IPSS) ${ }^{1}$ and the Determinants of Outcome of Severe Mental Disorders (DOS) study $^{2}$ were conducted over 25 years ago by the World Health Organization (WHO) to analyse regional differences in the incidence and outcomes of schizophrenia. Outcomes over 2-5 years varied among the different areas; participants living in low- and middle-income countries had better outcomes than those in high-income areas. ${ }^{3,4}$ This unexpected finding was confirmed in the long-term (15 and 25 years) International Study of Schizophrenia (ISoS) coordinated by the WHO., ${ }^{5,6}$ The reasons for better outcomes in low- and middle-income countries are not fully understood and much debated, but it has been suggested that sociocultural factors including close family support and interactions may play an important role. ${ }^{7}$

Some researchers have questioned whether schizophrenia really does have a better course and outcome in low- and middle-income countries. ${ }^{8,9}$ These authors highlighted the methodological limitations of the WHO studies, the lack of evidence on specific sociocultural factors as contributing to the better outcomes, and cited new evidence of poor prognosis of schizophrenia from studies in low- and middle-income countries.

In addition to the WHO studies, other long-term follow-up studies have focused on the course of schizophrenia. ${ }^{10-15}$ These studies have shown considerable heterogeneity in outcomes, but have tended to be single-country studies. There has not been any recent multinational study with a large enough sample size

See editorial, pp. 173-175, this issue to analyse whether the geographic differences in outcome seen in the WHO studies are still present today.

Studies have shown that more individuals with schizophrenia achieve clinical remission than functional remission, ${ }^{16}$ and some people may experience functional remission despite ongoing symptoms, ${ }^{17}$ indicating that different factors may predict symptom versus functional remission. However, clinical remission is associated with better functional outcome than non-remission. ${ }^{18}$

The aims of this study are to determine the frequency of symptom and functional remission in out-patients with schizophrenia in different regions of the world. We will also analyse the sociodemographic and clinical factors associated with both outcomes. We hypothesise that there will be differences in symptom and functional remission between regions, and that each dimension will follow different patterns.

\section{Method}

\section{Study design}

The Schizophrenia Outpatient Health Outcomes (SOHO) study was a 3-year, prospective, observational study primarily designed to assess the comparative costs and outcomes associated with antipsychotic use in out-patients initiating or changing antipsychotic medication for schizophrenia (with an emphasis on olanzapine compared with other antipsychotics). The SOHO study was conducted in 10 Western European countries, ${ }^{19,20}$ and in 27 countries across 4 continents as the Intercontinental SOHO (IC-SOHO). ${ }^{21}$ Both studies shared the same methodology. Threeyear data from both studies have been published elsewhere. ${ }^{22,23}$ 
Data from all 37 participating countries have been pooled to produce the Worldwide-SOHO (W-SOHO) data-set, which includes a total of 17384 participants. The SOHO studies were non-interventional, with all treatment (including flexible dosing and use of concomitant therapies and medications) at the discretion of the treating psychiatrist. No medications were provided by the study sponsor; investigators were free to prescribe any antipsychotic medication indicated for schizophrenia. Individuals were assessed at study entry and during scheduled study visits at $3,6,12,18,24,30$ and 36 months post-baseline. The study was approved and conducted in accordance with local (country) ethics and regulatory requirements; all participants consented to participate.

\section{Participant population}

To ensure the study population was representative as much as possible of actual clinical practice, minimal selection criteria were applied. All individuals aged 18 years or over, who met DSM-IV ${ }^{24}$ or ICD- $10^{25}$ criteria for schizophrenia, and who were initiating or changing antipsychotic medication at study entry in an out-patient, ambulatory or community setting (or in hospital during an admission scheduled for the initiation or change for up to 2 weeks) were considered eligible unless they were participating in another study that included a treatment intervention and/or an investigational drug. Study sites were established in 37 countries across 6 regions. Patient enrolment began in September 2000 for SOHO and in November 2000 for IC-SOHO; the last participant was enrolled in December 2001. The main objective of the study was to compare the outcomes of participants starting olanzapine with other antipsychotics. Participants were enrolled in two groups of similar size: one included those starting olanzapine, and the other included those starting any other antipsychotic. This deliberate oversampling of people taking olanzapine was done to facilitate comparisons between the two groups, as per the primary objective. Importantly, the antipsychotic treatment prescribed to each person was wholly based on the opinion of the treating psychiatrist; individuals were asked to participate in the study after they had received their medication prescription. The enrolment period was intentionally long to avoid interfering with standard medical practice and no minimum number of participants was required per participating psychiatrist.

\section{Measures}

All assessment tools were chosen for simplicity and ease of use, bearing in mind the observational nature of the study, cross-cultural relevance and practical needs such as translation into different languages. The Clinical Global Impressions Schizophrenia (CGI-SCH) scale ${ }^{26}$ was used to assess symptom severity across positive, negative, depressive and cognitive subdomains in addition to overall symptoms from 1 (normal, not at all ill) to 7 (among the most severely ill). A detailed patient history was taken at baseline, capturing clinical information (including duration of illness, current and past medications, reasons for treatment initiation or change, CGI-SCH score, adverse events) in addition to key sociodemographic, functional and health service use data such as age, alcohol and substance misuse/dependency, housing and employment status, suicidality, hostility (has the patient exhibited verbal or physical hostility/ aggression in the past 6 months?) and previous hospital admissions and out-patient clinic visits. This information was obtained from all available sources (direct patient and family interview, clinical chart). The location and type of the principal practice of participating investigators was also collected.

\section{Statistical analysis}

Only participants with at most one missing visit (except the final one) were included in the analysis. For participants with one missing visit, values from the previous visit were carried forward and used to impute the values of the missing visit. Results from the 3-month visit were not used in the analysis unless data from the 6-month visit were missing; in such cases, data from the 3-month visit were used in the imputation.

The 37 countries participating in the study were grouped into 6 regions as follows: North Europe (France, Germany, UK, The Netherlands, Ireland, Denmark); South Europe (Spain, Italy, Portugal, Greece, Israel (Israel has been included in the South Europe group based on ethnicity, economic and healthcare systems)); Central and Eastern Europe (Czech Republic, Hungary, Lithuania, Poland, Romania, Russia, Slovakia, Slovenia); Latin America (Argentina, Chile, Colombia, Costa Rica, El Salvador, Guatemala, Honduras, Mexico, Peru, Puerto Rico, Venezuela); North Africa and Middle East (Algeria, Egypt, Saudi Arabia, Turkey); and East Asia (Korea, Malaysia, Taiwan).

Approximately a third of the participants $(36.3 \%)$ were lost to follow-up before the end of the study at 3 years and were not included in the analysis. The percentage varied across regions. The highest attrition rate was in East Asia (62.8\%), followed by Africa and Middle East (47.7\%), Latin America (41.7\%), North Europe (37.5\%), South Europe (28.2\%) and Central and Eastern Europe $(26.9 \%)$. There were small differences in participant characteristics between those included and not included in the analyses, both overall and by region. All statistical analyses were done using SAS version 9.1 for Windows.

\section{Definition of remission}

Clinical remission was defined as achieving CGI-SCH overall, positive, negative and cognitive symptom scores lower than or equal to 3 on the scale from 1 to 7 for 6 months (i.e. for two consecutive visits) plus no in-patient admission during the same period. As two consecutive visits were considered this meant clinical remission could not occur before the 12-month visit. This definition of clinical remission was based on the Andreasen criteria as presented and validated in previous reports of the SOHO study. ${ }^{26,27}$

Functional remission was defined as having good social functioning for a period of 6 months (two consecutive visits). Good social functioning included those participants who had: (a) a positive occupational/vocational status, i.e. paid or unpaid full- or part-time employment, being an active student in university or housewife; (b) independent living; and (c) active social interactions, i.e. having more than one social contact during the past 4 weeks or having a spouse or partner. Functional remission was also defined from the 12-month visit.

\section{Descriptive analysis}

Baseline characteristics were described overall and for each of the six regions for those participants with no more than one missing visit $(n=11078)$. In addition, the baseline characteristics of participants who did and did not achieve clinical remission and functional remission at some point during the 3-year follow-up were summarised using descriptive statistics. Differences between the groups who did and did not achieve remission were compared using chi-squared or Fisher's exact tests for categorical data and Wilcoxon or Mann-Whitney tests for numerical variables. For all comparisons, the level of significance was 0.05 . The baseline sociodemographic and clinical variables compared included: number of participants, gender, age, previously untreated, age at first treatment for schizophrenia, duration of illness (years since 
first treatment for schizophrenia), alcohol dependency, substance misuse, suicide attempts, overall CGI-SCH, positive CGI-SCH, negative CGI-SCH, depressive CGI-SCH, cognitive CGI-SCH, hostility, adherence, body mass index, marital status, living independently, having paid employment and being socially active.

\section{Regression model}

Logistic regression models were used to identify variables independently associated with clinical remission and those associated with functional remission for the overall W-SOHO sample. Stepwise model reduction was conducted by dropping from the model any non-significant variables. Data from the logistic regression models are presented as odds ratios (OR), 95\% confidence intervals and $P$-values. The CGI was treated as a continuous variable in the models. The odds ratios in this case and other continuous variables estimate the change in the response variable by point of change in variable. The logistic regression models were repeated by region, including all significant covariates in any of the regions.

\section{Results}

The overall W-SOHO sample analysed included 11078 participants with at most one missing visit. The number of participants in each of the six regions was: South Europe $(n=4154)$; North Europe $(n=2682)$; Central and Eastern Europe $(n=1589)$; Latin America $(n=1497)$; North Africa and Middle East $(n=701)$; and East Asia $(n=455)$. Table 1 summarises the baseline characteristics of the overall W-SOHO sample and of participants in each of the six regions.

Of the 11078 participants analysed, 7322 (66.1\%) achieved clinical remission during the 3-year follow-up, whereas only $2811(25.4 \%)$ achieved functional remission during follow-up. Table 2 summarises the frequency of clinical and functional remission for each of the six regions. The frequency of clinical remission ranged from $60.1 \%$ in North Europe to $84.4 \%$ in East Asia, and the frequency of functional remission ranged from $17.8 \%$ in North Africa and Middle East to $35.0 \%$ in North Europe.

Compared with participants who did not achieve clinical remission, those who achieved clinical remission in the overall sample were more frequently women, younger, had a shorter duration of illness, previously untreated, had less alcohol and substance misuse in the past, fewer suicide attempts in the past, had a good level of social functioning at baseline (more frequently working for pay, having a spouse or partner, living independently and being socially active) and lower symptoms at baseline (Table 3). Similarly, comparisons between participants who did and did not achieve functional remission (Table 3) showed that those achieving functional remission also had an older age at first contact and displayed less hostility at baseline, but had no difference in depressive symptoms at baseline or a history of substance misuse and suicide attempts.

Logistic regression analysis of factors independently associated with achieving clinical remission at some point during the 3-year follow-up for the overall sample (Table 4) showed that region was one of the most important predictors of clinical remission: compared with South Europe, individuals in the regions of North Africa and Middle East, Latin America and East Asia were significantly more likely to achieve clinical remission. Other baseline factors significantly associated with an increased likelihood of clinical remission were: being female, first treatment for schizophrenia ever, having good social functioning at baseline (paid employment, spouse/partner, being socially active), displaying hostile behaviour and having higher depressive symptoms at baseline. In contrast, older age at first treatment, a longer duration of illness, history of substance misuse and higher clinical severity at baseline (overall severity, positive, negative and cognitive symptoms) were associated with a lower likelihood of achieving clinical remission.

Table 1 Baseline characteristics of the Worldwide Schizophrenia Outpatient Health Outcomes (W-SOHO) sample $(n=11078)$ and participants in each of the six regions ${ }^{a}$

\begin{tabular}{|c|c|c|c|c|c|c|c|}
\hline & $\begin{array}{c}\text { East } \\
\text { Asia } \\
(n=455)\end{array}$ & $\begin{array}{l}\text { North Africa } \\
\text { and Middle } \\
\text { East }(n=701)\end{array}$ & $\begin{array}{c}\text { Latin } \\
\text { America } \\
(n=1497)\end{array}$ & $\begin{array}{l}\text { Central and } \\
\text { Eastern Europe } \\
\quad(n=1589)\end{array}$ & $\begin{array}{c}\text { North } \\
\text { Europe } \\
(n=2682)\end{array}$ & $\begin{array}{c}\text { South } \\
\text { Europe } \\
(n=4154)\end{array}$ & $\begin{array}{c}\text { Total } \\
(n=11078)\end{array}$ \\
\hline Male, \% & 53.5 & 62.3 & 57.3 & 47.9 & 52.2 & 61.0 & 56.3 \\
\hline Never treated, \% & 3.3 & 8.9 & 10.5 & 5.4 & 10.7 & 8.8 & 8.8 \\
\hline Age, years: median (IQR) & $33.3(56.1)$ & $31.8(54.4)$ & $34.4(60.5)$ & $37.4(61.9)$ & $39.9(71.4)$ & $29.8(71.0)$ & $37.1(71.5)$ \\
\hline Age at first treatment, years: median (IQR) & $25.0(53.0)$ & $24.0(61.0)$ & $22.0(50.0)$ & $27.0(61.0)$ & $28.0(79.0)$ & $25.0(70.0)$ & $25.0(79.0)$ \\
\hline Duration of illness, years: median (IQR) & $7.4(55.1)$ & $5.8(38.9)$ & $9.1(56.5)$ & $7.0(51.0)$ & $7.9(65.3)$ & $9.8(63.9)$ & $8.5(65.3)$ \\
\hline \multicolumn{8}{|l|}{ CGI-SCH score, ${ }^{\mathrm{b}}$ mean (s.d.) } \\
\hline Overall severity & $3.8(1.0)$ & $4.7(1.1)$ & $4.5(1.1)$ & $4.2(0.9)$ & $4.3(1.0)$ & $4.5(1.0)$ & $4.4(1.0)$ \\
\hline Positive & $3.7(1.3)$ & $4.5(1.4)$ & $4.1(1.3)$ & $3.5(1.4)$ & $3.7(1.4)$ & $3.9(1.4)$ & $3.8(1.4)$ \\
\hline Negative & $3.2(1.2)$ & $4.1(1.4)$ & $4.0(1.4)$ & $4.1(1.2)$ & $4.0(1.3)$ & $4.1(1.3)$ & $4.0(1.3)$ \\
\hline Depressive & $2.8(1.1)$ & $3.3(1.5)$ & $3.4(1.5)$ & $3.3(1.3)$ & $3.4(1.4)$ & $3.5(1.3)$ & $3.4(1.3)$ \\
\hline Cognitive & $2.8(1.2)$ & $3.8(1.4)$ & $3.9(1.4)$ & $3.9(1.2)$ & $3.9(1.3)$ & $3.7(1.3)$ & $3.8(1.3)$ \\
\hline Alcohol misuse ever, \% & 3.8 & 9.4 & 11.1 & 8.0 & 10.9 & 13.1 & 10.9 \\
\hline Substance misuse ever, \% & 3.1 & 5.1 & 10.2 & 3.4 & 9.8 & 12.2 & 9.2 \\
\hline Any suicide attempt ever, \% & 23.6 & 23.0 & 27.9 & 25.7 & 31.0 & 22.3 & 25.7 \\
\hline Hostility, \% & 27.1 & 47.8 & 40.1 & 23.0 & 22.3 & 29.6 & 29.4 \\
\hline Having a spouse or partner, \% & 39.2 & 29.1 & 29.1 & 38.0 & 36.6 & 24.7 & 30.9 \\
\hline Living independently, \% & 31.2 & 24.0 & 24.1 & 48.7 & 62.7 & 37.2 & 42.2 \\
\hline Paid employment, \% & 16.3 & 19.1 & 17.6 & 20.0 & 23.2 & 17.3 & 19.2 \\
\hline Socially active, \% & 61.9 & 42.4 & 55.3 & 60.7 & 73.2 & 66.3 & 64.0 \\
\hline
\end{tabular}




\begin{tabular}{|c|c|c|}
\hline & $\begin{array}{l}\text { Clinical } \\
\text { remission } \\
n / N(\%)^{\mathrm{a}}\end{array}$ & $\begin{array}{c}\text { Functional } \\
\text { remission } \\
n / N(\%)^{\mathrm{a}}\end{array}$ \\
\hline East Asia & 384/455 (84.4) & $112 / 455(24.6)$ \\
\hline North Africa and Middle East & 558/701 (79.6) & 125/701 (17.8) \\
\hline Latin America & 1189/1497 (79.4) & 430/1497 (28.7) \\
\hline Central and Eastern Europe & $1034 / 1589(65.1)$ & $344 / 1589(21.6)$ \\
\hline North Europe & $1611 / 2682(60.1)$ & 940/2682 (35.0) \\
\hline South Europe & 2546/4154 (61.3) & 860/4154 (20.7) \\
\hline Total & 7322/11 078 (66.1) & 2811/11 078 (25.4) \\
\hline
\end{tabular}

Logistic regression showed that region was also an important predictor of achieving functional remission (Table 4): compared with participants in South Europe, those in Latin America and North Europe were significantly more likely to achieve functional remission, whereas individuals in Central and Eastern Europe were significantly less likely to achieve functional remission. Baseline social functioning (independent housing, paid employment, spouse/partner and being socially active) was another important predictor of functional remission, together with being female, never treated for schizophrenia before study entry and a higher depressive symptom score at baseline. Older age at first treatment and a longer duration of illness were significantly associated with less likelihood of functional remission. The magnitude of the effect of independent housing and having paid employment at baseline on functional remission was particularly large (odds ratio around 6).

Table 5 summarises the baseline factors independently associated with achieving clinical remission and Table 6 those for achieving functional remission for each of the six regions.
Being previously untreated was generally associated with a greater chance of clinical remission across all regions, whereas a higher negative symptoms score was associated with less chance of clinical remission. The strongest predictors of an increased odds of functional remission across all or nearly all regions were the social functioning variables (being in paid employment, living in independent housing or being socially active). Being female, previously treated, and having a spouse/partner was associated with a greater chance of functional remission in some regions, whereas an older age at first treatment and a longer duration of illness were associated with less chance of remission in all three European regions and Latin America.

\section{Discussion}

\section{Study limitations}

The W-SOHO study is the largest prospective observational study on the outcome of schizophrenia in an out-patient setting. However, there are several limitations that must be considered when discussing the results. First, although the 37 countries participating in the $\mathrm{W}-\mathrm{SOHO}$ study belong to 6 regions of the world with different economic and cultural characteristics, the countries are not necessarily representative of these regions and some regions, such as East Asia, had a relatively small number of participants. In addition, the centres or investigators participating in the study in each country may not be representative of the whole country. Second, although sociodemographic and clinical characteristics were assessed in individuals participating and were taken into account in the analyses, we cannot rule out that different types of individuals with schizophrenia were enrolled in different countries, that there were other confounding variables not recorded in the study and that service contexts and residual confounding may be influencing the results. Third, we did not collect detailed information on the cultural environment of the participants, which could have influenced outcomes, and limits the exploration of the reasons for the regional differences. Fourth,

Table 3 Baseline characteristics of participants achieving and not achieving clinical or functional remission in the W-SOHO sample $(n=11078)$

\begin{tabular}{|c|c|c|c|c|c|c|}
\hline & \multicolumn{3}{|c|}{ Clinical remission } & \multicolumn{3}{|c|}{ Functional remission } \\
\hline & $\begin{array}{l}\text { Remission } \\
(n=7322)\end{array}$ & $\begin{array}{l}\text { No remission } \\
\quad(n=3756)\end{array}$ & $P$ & $\begin{array}{l}\text { Remission } \\
(n=2811)\end{array}$ & $\begin{array}{l}\text { No remission } \\
(n=8267)\end{array}$ & $P$ \\
\hline Male, \% & 54.3 & 60.2 & $<0.0001$ & 47.5 & 59.3 & $<0.0001$ \\
\hline Never treated, \% & 10.5 & 5.5 & $<0.0001$ & 13.7 & 7.1 & $<0.0001$ \\
\hline Age, years: median (IQR) & 37.7 (12.3) & $41.0(12.8)$ & $<0.0001$ & 37.5 (10.5) & $39.3(13.2)$ & $<0.0001$ \\
\hline Age of first treated, mean (s.d.) & $27.7(9.7)$ & $27.8(10.1)$ & 0.6540 & $28.7(8.9)$ & $27.4(10.1)$ & $<0.0001$ \\
\hline Duration of illness, mean (s.d.) & $10.2(10.0)$ & $13.3(11.4)$ & $<0.0001$ & $9.1(9.1)$ & $12.0(11.0)$ & $<0.0001$ \\
\hline \multicolumn{7}{|l|}{ CGI-SCH score, mean (s.d.) } \\
\hline Overall severity & $4.2(1.0)$ & $4.7(0.9)$ & $<0.0001$ & $4.2(1.1)$ & $4.4(1.0)$ & $<0.0001$ \\
\hline Positive & $3.7(1.4)$ & $4.1(1.4)$ & $<0.0001$ & $3.7(1.5)$ & $3.9(1.4)$ & $<0.0001$ \\
\hline Negative & $3.8(1.3)$ & $4.5(1.2)$ & $<0.0001$ & $3.7(1.3)$ & $4.1(1.3)$ & $<0.0001$ \\
\hline Depressive & $3.3(1.3)$ & $3.6(1.3)$ & $<0.0001$ & $3.4(1.4)$ & $3.4(1.3)$ & 0.3359 \\
\hline Cognitive & $3.6(1.3)$ & $4.2(1.2)$ & $<0.0001$ & $3.6(1.3)$ & $3.8(1.3)$ & $<0.0001$ \\
\hline Alcohol misuse ever, \% & 10.0 & 12.8 & $<0.0001$ & 9.0 & 11.6 & 0.0001 \\
\hline Substance misuse ever, \% & 8.6 & 10.5 & 0.0009 & 8.4 & 9.5 & 0.0841 \\
\hline Any suicide attempt ever, \% & 24.1 & 29.2 & $<0.0001$ & 24.7 & 26.1 & 0.1536 \\
\hline Hostility, \% & 29.5 & 29.0 & 0.5607 & 25.0 & 30.8 & $<0.0001$ \\
\hline Having a spouse or partner, $\%$ & 33.9 & 25.2 & $<0.0001$ & 52.5 & 23.6 & $<0.0001$ \\
\hline Living independently, \% & 43.7 & 39.1 & $<0.0001$ & 75.1 & 31.0 & $<0.0001$ \\
\hline Paid employment, \% & 22.8 & 12.1 & $<0.0001$ & 45.4 & 10.3 & $<0.0001$ \\
\hline Socially active, \% & 67.0 & 58.2 & $<0.0001$ & 74.8 & 60.3 & $<0.0001$ \\
\hline
\end{tabular}


Table 4 Baseline factors associated with achieving clinical and functional remission during the 3-year follow-up for the W-SOHO sample $(n=11078)^{\mathrm{a}}$

\begin{tabular}{|c|c|c|c|c|c|c|}
\hline & \multicolumn{3}{|c|}{ Clinical remission } & \multicolumn{3}{|c|}{ Functional remission } \\
\hline & Odds ratio & $95 \% \mathrm{Cl}$ & $P$ & Odds ratio & $95 \% \mathrm{Cl}$ & $P$ \\
\hline North Africa and Middle East (v. South Europe) & 2.82 & $2.19-3.64$ & $<0.0001$ & 0.89 & $0.66-1.20$ & 0.4293 \\
\hline Central and Eastern Europe (v. South Europe) & 0.91 & $0.78-1.05$ & 0.1893 & 0.71 & $0.59-0.86$ & 0.0004 \\
\hline East Asia (v. South Europe) & 1.87 & $1.37-2.55$ & $<0.0001$ & 1.02 & $0.75-1.39$ & 0.8843 \\
\hline Latin America (v. South Europe) & 2.50 & $2.11-2.96$ & $<0.0001$ & 2.14 & $1.77-2.59$ & $<0.0001$ \\
\hline North Europe (v. South Europe) & 0.79 & $0.69-0.89$ & 0.0002 & 1.34 & $1.15-1.56$ & 0.0002 \\
\hline Female ( $v$. male) & 1.28 & $1.15-1.42$ & $<0.0001$ & 1.60 & $1.42-1.81$ & $<0.0001$ \\
\hline Age at first treatment & 0.99 & $0.98-0.99$ & $<0.0001$ & 0.97 & $0.96-0.97$ & $<0.0001$ \\
\hline Duration of illness & 0.98 & $0.97-0.98$ & $<0.0001$ & 0.96 & $0.96-0.97$ & $<0.0001$ \\
\hline Never treated (yes v. no) & 2.01 & $1.62-2.50$ & $<0.0001$ & 1.50 & $1.21-1.86$ & 0.0002 \\
\hline Alcohol misuse (yes v. no) & 0.98 & $0.83-1.16$ & 0.8319 & 0.86 & $0.68-1.07$ & 0.1664 \\
\hline Substance misuse (yes v. no) & 0.78 & $0.65-0.94$ & 0.0083 & 1.06 & $0.84-1.34$ & 0.5973 \\
\hline \multicolumn{7}{|l|}{ CGI-SCH score } \\
\hline Overall severity & 0.75 & $0.69-0.82$ & $<0.0001$ & 0.99 & $0.90-1.09$ & 0.8388 \\
\hline Positive & 0.91 & $0.87-0.95$ & $<0.0001$ & 0.99 & $0.94-1.05$ & 0.7742 \\
\hline Negative & 0.79 & $0.74-0.83$ & $<0.0001$ & 0.95 & $0.89-1.01$ & 0.0991 \\
\hline Depressive & 1.08 & $1.03-1.12$ & 0.0008 & 1.07 & $1.02-1.13$ & 0.0087 \\
\hline Cognitive & 0.85 & $0.81-0.90$ & $<0.0001$ & 0.96 & $0.91-1.02$ & 0.1916 \\
\hline Hostile behaviours (yes v. no) & 1.19 & $1.06-1.33$ & 0.0028 & 0.91 & $0.79-1.05$ & 0.1829 \\
\hline Spouse or partner (yes v. no) & 1.35 & $1.20-1.51$ & $<0.0001$ & 2.16 & $1.90-2.45$ & $<0.0001$ \\
\hline Independent housing ( $v$. dependent housing) & 1.08 & $0.97-1.21$ & 0.1786 & 6.00 & $5.22-6.89$ & $<0.0001$ \\
\hline Paid employment (v. unemployed/unpaid) & 1.47 & $1.27-1.69$ & $<0.0001$ & 5.66 & $4.94-6.48$ & $<0.0001$ \\
\hline Socially active (v. no social activities) & 1.22 & $1.10-1.35$ & 0.0002 & 1.50 & $1.32-1.71$ & $<0.0001$ \\
\hline
\end{tabular}

\begin{tabular}{|c|c|c|c|c|c|c|}
\hline & \multicolumn{6}{|c|}{ Odds ratio $(95 \% \mathrm{Cl})$} \\
\hline & $\begin{array}{l}\text { East } \\
\text { Asia }\end{array}$ & $\begin{array}{c}\text { North Africa } \\
\text { and Middle East }\end{array}$ & $\begin{array}{l}\text { Latin } \\
\text { America }\end{array}$ & $\begin{array}{l}\text { Central and } \\
\text { Eastern Europe }\end{array}$ & $\begin{array}{l}\text { North } \\
\text { Europe }\end{array}$ & $\begin{array}{l}\text { South } \\
\text { Europe }\end{array}$ \\
\hline Female ( $v$. male) & $1.26(0.62-2.58)$ & $1.78(1.03-3.08)^{\star}$ & $0.85(0.61-1.17)$ & $1.40(1.09-1.78)^{*}$ & $1.09(0.89-1.34)$ & $1.46(1.23-1.73)^{*}$ \\
\hline Age at first treatment & $0.97(0.93-1.01)$ & $0.98(0.95-1.02)$ & $0.98(0.96-1.00)$ & $0.98(0.97-1.00)^{*}$ & $0.99(0.98-1.00)$ & $0.99(0.98-1.00)^{*}$ \\
\hline Duration of illness & $1.00(0.96-1.03)$ & $0.98(0.95-1.01)$ & $0.96(0.94-0.07)^{*}$ & $0.97(0.96-0.99)^{*}$ & $0.98(0.97-0.99)^{*}$ & $0.97(0.97-0.98)^{\star}$ \\
\hline Never treated (yes $v$. no) & $2.67(0.29-24.57)$ & $1.51(0.50-4.52)$ & $2.12(1.08-4.19)^{*}$ & $2.42(1.23-4.75)^{\star}$ & $2.77(1.84-4.16)^{*}$ & $1.57(1.12-2.12)^{\star}$ \\
\hline Alcohol misuse (yes v. no) & $0.14(0.03-0.76)^{*}$ & $0.80(0.33-1.91)$ & $0.73(0.42-1.26)$ & $1.83(1.11-3.00)^{*}$ & $0.97(0.70-1.35)$ & $0.91(0.70-1.17)$ \\
\hline Substance misuse (yes v. no) & $2.28(0.27-19.04)$ & $0.96(0.28-3.23)$ & $1.13(0.62-2.08)$ & $0.61(0.31-1.19)$ & $0.64(0.45-0.90)^{*}$ & $0.86(0.66-1.12)$ \\
\hline Suicide attempts in past (yes $v$. no) & $0.71(0.35-1.43)$ & $0.72(0.41-1.26)$ & $0.92(0.66-1.28)$ & $1.16(0.88-1.54)$ & $1.05(0.84-1.30)$ & $0.85(0.70-1.02)$ \\
\hline \multicolumn{7}{|l|}{ CGI-SCH score } \\
\hline Overall severity & $0.92(0.49-1.73)$ & $0.69(0.46-1.03)$ & $0.95(0.74-1.22)$ & $0.59(0.47-0.74)^{*}$ & $0.67(0.56-0,80)^{*}$ & $0.79(0.70-0.90)^{*}$ \\
\hline Positive & $0.74(0.49-1.11)$ & $1.07(0.84-1.36)$ & $0.90(0.77-1.04)$ & $0.92(0.82-1.02)$ & $0.87(0.80-0.95)^{*}$ & $0.92(0.86-0.99)^{*}$ \\
\hline Negative & $0.71(0.48-1.04)$ & $0.76(0.59-0.99)^{*}$ & $0.83(0.71-0.97)^{*}$ & $0.84(0.73-0.97)^{*}$ & $0.82(0.74-0.91)^{*}$ & $0.75(0.68-0.81)^{\star}$ \\
\hline Depressive & $1.10(0.80-1.52)$ & $0.95(0.78-1.17)$ & $1.02(0.91-1.15)$ & $1.25(1.12-1.39)^{*}$ & $1.06(0.97-1.15)$ & $1.09(1.01-1.17)^{*}$ \\
\hline Cognitive & $0.76(0.55-1.05)$ & $0.85(0.65-1.09)$ & $0.84(0.72-0.97)^{\star}$ & $0.92(0.80-1.05)$ & $0.87(0.78-0.97)^{*}$ & $0.85(0.79-0.92)^{*}$ \\
\hline Hostile behaviours (yes v. no) & $0.87(0.42-1.79)$ & $1.06(0.63-1.77)$ & $1.14(0.83-1.57)$ & $1.03(0.76-1.39)$ & $1.67(1.32-2.13)^{*}$ & $1.09(0.91-1.29)$ \\
\hline Spouse or partner (yes v. no) & $1.33(0.64-2.75)$ & $1.89(0.93-3.82)$ & $1.81(1.21-2.70)^{*}$ & $1.32(1.01-1.72)^{\star}$ & $1.20(0.97-1.50)$ & $1.34(1.09-1.65)^{*}$ \\
\hline Independent housing ( $v$. dependent housing) & $0.71(0.34-1.50)$ & $0.90(0.44-1.81)$ & $2.19(1.39-3.45)^{*}$ & $1.06(0.81-1.39)$ & $1.10(0.89-1.37)$ & $0.98(0.82-1.18)$ \\
\hline Paid employment (v. unemployed/unpaid) & $2.96(0.78-11.21)$ & $0.87(0.43-1.75)$ & $0.64(0.41-1.01)$ & $1.28(0.91-1.80)$ & $1.74(1.34-2.25)^{*}$ & $1.77(1.40-2.25)^{\star}$ \\
\hline Socially active (v. no social activities) & $1.32(0.66-2.63)$ & $1.39(0.81-2.39)$ & $1.37(1.00-1.86)^{*}$ & $1.03(0.80-1.33)$ & $1.16(0.93-1.44)$ & $1.28(1.08-1.51)^{\star}$ \\
\hline
\end{tabular}

data were collected at 6-month intervals and limited information was gathered between assessment visits. Fifth, data were only collected over 3 years and, therefore, are unlikely to represent the full course of schizophrenia: some individuals may have experienced remission at a later time. Sixth, given the limitations of the ascertainment tools, our methods do not allow us to separate the effects of regional clinical practices (and therefore their ratings on the CGI-SCH) of the participating psychiatrists from the predictors of outcome analysed. Seventh, interrater reliability was not assessed given the large number of participating investigators. However, measures were chosen based on clarity and ease of use. Eighth, participants included in the analysis are those 
Table 6 Baseline factors associated with achieving functional remission during the 3-year follow-up for each of the six regions

\begin{tabular}{|c|c|c|c|c|c|c|}
\hline & \multicolumn{6}{|c|}{ Odds ratio $(95 \% \mathrm{Cl})$} \\
\hline & $\begin{array}{l}\text { East } \\
\text { Asia }\end{array}$ & $\begin{array}{l}\text { North Africa and } \\
\text { Middle East }\end{array}$ & $\begin{array}{l}\text { Latin } \\
\text { America }\end{array}$ & $\begin{array}{l}\text { Central and } \\
\text { Eastern Europe }\end{array}$ & $\begin{array}{l}\text { North } \\
\text { Europe }\end{array}$ & $\begin{array}{l}\text { South } \\
\text { Europe }\end{array}$ \\
\hline Female (v. male) & $0.59(0.33-1.05)$ & $1.50(0.77-2.90)$ & $1.68(1.22-2.31)^{*}$ & $1.18(0.83-1.66)$ & $1.41(1.12-1.78)^{*}$ & $2.28(1.81-2.86)^{*}$ \\
\hline Age at first treatment & $0.99(0.95-1.03)$ & $1.01(0.98-1.06)$ & $0.97(0.95-0.99)^{*}$ & $0.95(0.93-0.97)^{\star}$ & $0.95(0.94-0.96)^{*}$ & $0.98(0.97-0.99)^{*}$ \\
\hline Duration of illness & $1.01(0.98-1.05)$ & $0.99(0.95-1.03)$ & $0.97(0.95-0.98)^{*}$ & $0.95(0.92-0.97)^{*}$ & $0.95(0.93-0.96)^{*}$ & $0.96(0.95-0.98)^{*}$ \\
\hline Never treated (yes $v$. no) & $0.94(0.16-5.41)$ & $2.02(0.59-6.92)$ & $1.85(1.15-2.97)^{\star}$ & $2.80(1.41-5.56)^{*}$ & $1.37(0.93-2.03)$ & $1.23(0.82-1.84)$ \\
\hline Alcohol misuse (yes v. no) & $0.42(0.07-2.58)$ & $1.75(0.56-5.45)$ & $0.88(0.49-1.58)$ & $0.66(0.30-1.45)$ & $1.00(0.68-1.48)$ & $0.70(0.47-1.04)$ \\
\hline Substance misuse (yes $v$. no) & $0.81(0.10-6.49)$ & $0.67(0.14-3.27)$ & $1.46(0.81-2.64)$ & $0.49(0.15-1.62)$ & $1.18(0.79-1.76)$ & $1.08(0.73-1.60)$ \\
\hline Suicide attempts in past (yes $v$. no) & $1.05(0.57-1.94)$ & $0.84(0.39-1.79)$ & $0.94(0.66-1.34)$ & $1.14(0.78-1.67)$ & $1.05(0.82-1.35)$ & $0.92(0.71-1.20)$ \\
\hline \multicolumn{7}{|l|}{ CGI-SCH score } \\
\hline Overall severity & $1.13(0.69-187)$ & $1.31(0.81-2.11)$ & $0.78(0.61-0.99)^{*}$ & $1.00(0.74-1.36)$ & $0.87(0.71-1.06)$ & $1.07(0.89-1.27)$ \\
\hline Positive & $0.88(0.62-1.14)$ & $0.99(0.72-1.35)$ & $1.09(0.94-1.26)$ & $0.88(0.76-1.02)$ & $0.98(0.89-1.09)$ & $1.02(0.93-1.12)$ \\
\hline Negative & $0.82(0.60-1.13)$ & $0.84(0.60-1.15)$ & $1.13(0.97-1.32)$ & $0.81(0.67-0.97)^{*}$ & $0.94(0.83-1.06)$ & $0.97(0.86-1.09)$ \\
\hline Depressive & $0.97(0.73-1.29)$ & $1.18(0.90-1.54)$ & $1.06(0.94-1.19)$ & $1.10(0.94-1.28)$ & $1.05(0.95-1.16)$ & $1.14(1.03-1.27)^{*}$ \\
\hline Cognitive & $0.99(0.73-1.35)$ & $0.93(0.66-1.32)$ & $1.00(0.87-1.16)$ & $0.96(0.80-1.16)$ & $1.01(0.89-1.14)$ & $0.95(0.86-1.05)$ \\
\hline Hostile behaviours (yes v. no) & $0.91(0.49-1.71)$ & $0.94(0.48-1.81)$ & $0.80(0.58-1.10)$ & $0.91(0.60-1.37)$ & $0.96(0.73-1.27)$ & $0.92(0.72-1.18)$ \\
\hline Spouse or partner (yes $v$. no) & $0.88(0.49-1.56)$ & $3.61(1.82-7.16)^{\star}$ & $2.34(1.67-3.28)^{*}$ & $2.29(1.61-3.27)^{\star}$ & $1.69(1.33-2.15)^{\star}$ & $2.69(2.14-3.38)^{*}$ \\
\hline Independent housing ( $v$. dependent housing) & $2.70(1.47-4.98)^{*}$ & $7.98(4.07-15.66)^{*}$ & $5.52(3.92-7.79)^{\star}$ & $2.45(1.70-3.54)^{\star}$ & $6.47(4.85-8.63)^{\star}$ & $8.96(6.96-11.52)^{*}$ \\
\hline Paid employment ( $v$. unemployed/unpaid) & $1.94(0.99-3.78)$ & $7.57(3.73-15.36)^{*}$ & $3.54(2.44-5.12)^{*}$ & $11.20(7.86-15.96)^{*}$ & * $6.29(4.85-8.17)^{\star}$ & $6.26(4.85-8.07)^{*}$ \\
\hline Socially active (v. no social activities) & $2.26(1.17-4.38)^{*}$ & $1.06(0.56-1.98)$ & $1.41(1.04-1.93)^{\star}$ & $1.49(1.03-2.15)^{*}$ & $1.96(1.50-2.57)^{\star}$ & $1.37(1.08-1.73)^{\star}$ \\
\hline
\end{tabular}

requiring a treatment change in routine clinical practice, which allowed us to study treatment outcomes but are obviously not representative of the overall patient population. Ninth, attrition was highest in the regions with the highest remission rates, which could explain some of the findings if attrition was higher in individuals with severe schizophrenia. Finally, our definition of clinical remission required a low level of symptoms for at least 6 months, consistent with the definition proposed by Andreasen. ${ }^{28}$ However, our definition of remission was based on the CGI-SCH, which is a valid but less specific measure of clinical severity than other scales such as the Positive and Negative Syndrome Scale (PANSS). ${ }^{29}$ Previous analyses have shown a good agreement between this and Andreasen's definition. ${ }^{27}$

\section{Regional differences in outcomes}

With these limitations in mind, the results of the W-SOHO study show that the clinical outcomes of schizophrenia seem to be worse in Europe compared with other regions. Remarkably, the regional differences were different for functional remission. The frequency of clinical remission was lower in the three European regions (6065\%) than in East Asia, Latin America, and North Africa and Middle East (79-84\%). Participants living in the latter three regions had a much greater likelihood of achieving clinical remission than those living in South Europe. Moreover, the variations in clinical remission rates between regions were not accounted for by differences in baseline clinical and sociodemographic characteristics evaluated in the study. Economic development, cultural factors such as family support or other country characteristics may explain the differences. Differences in economic development are not necessarily translated to differences in the course of schizophrenia. For example, South Europe and Central and Eastern Europe show similar clinical remission rates but have different levels of economic development. Our findings support the earlier WHO studies reporting differences in outcomes between regions. ${ }^{1-6}$
However, regional differences in functional remission followed a different pattern. Although it was more likely for individuals in Latin America to achieve functional remission compared with South Europe, there were no clear differences with East Asia or North Africa and Middle East. A new pattern emerged when compared with Central and Eastern Europe and North Europe; Central and Eastern Europe seemed to have a lower functional remission rate compared with South Europe, whereas North Europe tended to have a higher functional remission rate.

When comparing the descriptive and regression differences between the regions, we wanted to highlight that the logistic model showed that individuals with schizophrenia in Central and Eastern Europe were significantly less likely to achieve functional remission than those in South Europe. However, this was not detected in the descriptive analysis, probably due to the fact that some social functioning variables (independent housing and having a spouse/partner) are confounding variables.

Although this is somewhat speculative, differences in remission rates seem to be the result of economic, cultural and environmental factors more than differences in schizophrenic disorder. The same diagnostic criteria were applied in all regions and similarities in predictors of outcome were seen across the regions, which may indicate similar characteristics of the disorder. The reasons for the better clinical outcome in low- and middleincome countries are unknown but may be related to differences in the balance between treatment and vulnerability experienced by the individuals. ${ }^{30}$ Differences in functional remission between regions were mostly driven by differences in independent living and paid employment. Thus, these differences in functional remission rates may be influenced by differences in access to accommodation, the presence of rehabilitation services and social benefits, the development of specific policies for individuals with severe mental disorders and the level of societal stigma about mental illness.

Our results indicate that there are several other baseline predictors of outcome. We found that women were more likely to achieve remission compared with men. This is consistent with 
many reports that women with schizophrenia experience better outcomes than men. ${ }^{31,32}$ Younger age, shorter duration of illness and no previous treatment for schizophrenia were also associated with a better chance of achieving remission, whereas substance misuse was associated with a lower chance of clinical remission, especially in North Europe. Our findings are consistent with systematic reviews and meta-analyses, which found that a shorter duration of untreated psychosis is associated with better symptomatic and functional outcomes in high-income and lowand middle-income countries. ${ }^{33,34}$ Although it has been reported that comorbid substance misuse is highly prevalent in schizophrenia and associated with poorer clinical outcomes, ${ }^{35}$ most of the evidence is based on studies in Western countries; the prevalence and impact of substance use disorders among people with schizophrenia in low- and middle-income countries has not been well studied. The frequency of alcohol or substance misuse was low in the overall $\mathrm{W}-\mathrm{SOHO}$ population at baseline compared with other samples, ${ }^{36}$ and its role as an independent predictor of remission varied across regions. Further work on substance misuse as a factor influencing outcome of schizophrenia across a wide range of countries is needed.

Higher symptom severity at baseline in terms of positive, negative, cognitive and overall symptoms was associated with less likelihood of clinical remission, but the severity of these symptoms was not significantly associated with functional remission. However, a higher level of depressive symptoms at baseline was associated with a higher likelihood of achieving both clinical and functional remission in the logistic regression analyses of the overall W-SOHO population. This supports previous findings that high levels of depressive symptoms at baseline predict favourable short-term outcomes in individuals with schizophrenia. ${ }^{37}$ However, other researchers have found that people with depressive symptoms have poorer long-term functional outcomes. ${ }^{38}$

Social functioning variables were important prognostic factors for remission in all regions. Participants with a spouse/partner, in paid employment and who were socially active at baseline were more likely to achieve clinical and functional remission, supporting previous findings that better baseline social functioning is associated with recovery (when defined as achieving symptomatic plus functional remission). ${ }^{17}$ The direction of the causality, however, may not be clear. For example, although working appears to help people recover from schizophrenia, ${ }^{39}$ the converse may also be true, i.e. individuals who maintain work are those who have a good prognosis. In the $\mathrm{W}$-SOHO population at baseline, the frequency of paid employment was low (19\%), ranging from $16 \%$ in East Asia to $23 \%$ in North Europe. This is similar to the employment rates reported for people with schizophrenia in Western countries, ${ }^{40}$ which vary both between and within countries. However, fully dissecting the role of social functioning on outcomes in schizophrenia is complicated because clinical changes can have an impact on social functioning. ${ }^{39}$ There are also high rates of stigma and discrimination against people with schizophrenia across countries, ${ }^{41}$ which can have an impact on their social functioning. ${ }^{42}$

The W-SOHO study has shown that there are cross-national differences in outcomes among out-patients with schizophrenia. Outcomes in terms of remission seem to be better for people living in low- and middle-income regions, especially Latin America. In general, the regional variation in outcome persisted even after adjusting for clinical and sociodemographic variables at baseline. Several predictive factors were identified suggesting that outcome differences are related to cultural and environmental factors rather than to differences in the disorder itself.
Josep Maria Haro, MD, PhD, Parc Sanitari Sant Joan de Déu, CIBER en Salud Mental (CIBERSAM), Sant Boi de Llobregat, Barcelona, Spain; Diego Novick, MD, El Lilly and Company, Windlesham, Surrey, UK, and Departament de Psiquiatria, Universitat Autonoma de Barcelona, Spain; Jordan Bertsch, MS, Parc Sanitari Sant Joan de Déu, CIBER en Salud Mental (CIBERSAM), Sant Boi de Llobregat, Barcelona, Spain; Jamie Karagianis, MD, Eli Lilly Canada Inc, Toronto, Ontario, Canada; Martin Dossenbach, MD, Eli Lilly Ges.m.b.H, Austria; Peter B. Jones, MD, Department of Psychiatry, University of Cambridge, UK

Correspondence: Josep Maria Haro, Parc Sanitari Sant Joan de Déu, Fundació Sant Joan de Déu, CIBERSAM, Dr. Antoni Pujadas, 42, 08830 - Sant Boi de Llobregat, Barcelona, Spain. Email: jmharo@fsjd.org

First received 3 May 2010, final revision 8 Mar 2011, accepted 21 Mar 2011

\section{Acknowledgements}

The authors thank Deirdre Elmhirst, PhD, for helping with the editorial development of this manuscript.

\section{References}

1 World Health Organization. Schizophrenia: An International Follow-up Study. John Wiley and Sons, 1979.

2 Jablensky A, Sartorius N, Ernberg G, Anker M, Korten A, Cooper JE, et al. Schizophrenia: manifestations, incidence and course in different cultures. A World Health Organisation ten-country study. Psychol Med Monograph Suppl 1992; 20: 1-97.

3 Sartorius N, Jablensky A, Shapiro R. Cross-cultural differences in the short-term prognosis of schizophrenic psychoses. Schizophr Bull 1978; 4 $102-13$.

4 Leff J, Sartorius N, Jablensky A, Korten A, Ernberg G. The International Pilot Study of Schizophrenia: five-year follow-up findings. Psychol Med 1992; 22: 131-45.

5 Harrison G, Hopper K, Craig T, Laska E, Siegel C, Wanderling J, et al. Recovery from psychotic illness: a 15- and 25-year international follow-up study. Br J Psychiatry 2001; 178: 506-17.

6 Hopper K, Wanderling J. Revisiting the developed versus developing country distinction in course and outcome in schizophrenia: results from ISOS, the WHO collaborative follow-up project. Schizophr Bull 2000; 26: 835-46.

7 Kulhara P, Chakrabarti S. Culture and schizophrenia and other psychotic disorders. Psychiatr Clin North Am 2001; 24: 449-64.

8 Cohen A, Patel V, Thara R, Gureje O. Questioning an axiom: better prognosis for schizophrenia in the developing world? Schizophr Bull 2008; 34: 229-44.

9 Patel V, Cohen A, Thara R, Gureje O. Is the outcome of schizophrenia really better in developing countries? Rev Bras Psiquiatr 2006; 28: 149-52.

10 Ciompi L. Catamnestic long-term study on the course of life and aging of schizophrenics. Schizophr Bull 1980; 6: 606-18.

11 Harding CM, Brooks GW, Ashikaga T, Strauss JS, Breier A. The Vermont longitudinal study of persons with severe mental illness, II: Long-term outcome of subjects who retrospectively met DSM-III criteria for schizophrenia. Am J Psychiatry 1987; 144: 727-35.

12 Huber G, Gross G, Schuttler R. A long-term follow-up study of schizophrenia: psychiatric course of illness and prognosis Acta Psychiatr Scand 1975; 52: 49-57.

13 Ogawa K, Miya M, Watarai A, Nakazawa M, Yuasa S, Utena H. A long-term follow-up study of schizophrenia in Japan - with special reference to the course of social adjustment. Br J Psychiatry 1987; 151: 758-65.

14 Robinson DG, Woerner MG, McMeniman M, Mendelowitz A, Bilder RM. Symptomatic and functional recovery from a first episode of schizophrenia or schizoaffective disorder. Am J Psychiatry 2004; 161: 473-9.

15 Shepherd M, Watt D, Fallon I, Smeeton N. The natural history of schizophrenia: a five-year follow-up study of outcome and prediction in a representative sample of schizophrenics. Psychol Med Monogr Suppl 1989; 15: $1-46$.

16 Lambert M, Schimmelmann BG, Naber D, Schacht A, Karow A, Wagner T, et al. Prediction of remission as a combination of symptomatic and functional remission and adequate subjective well-being in 2960 patients with schizophrenia. J Clin Psychiatry 2006; 67: 1690-7.

17 Wunderink L, Sytema S, Nienhuis FJ, Wiersma D. Clinical recovery in firstepisode psychosis. Schizophr Bull 2009; 35: 362-9.

18 Boden R, Sundstrom J, Lindstrom E, Lindstrom L. Association between symptomatic remission and functional outcomes in first-episode schizophrenia. Schizophr Res 2009; 107: 232-7. 
19 Haro JM, Edgell ET, Jones PB, Alonso J, Gavart S, Gregor KJ, et al. The European Schizophrenia Outpatient Health Outcomes (SOHO) Study: rationale, methods and recruitment. Acta Psychiatr Scand 2003; 107 222-32

20 Haro JM, Edgell ET, Novick D, Alonso J, Kennedy L, Jones PB, et al. Effectiveness of antipsychotic treatment for schizophrenia: 6-month results of the Pan-European Schizophrenia Outpatient Health Outcomes (SOHO) Study. Acta Psychiatr Scand 2005; 111: 220-31.

21 Dossenbach M, Arango-Davila C, Silva Ibarra H, Landa E, Aguilar J, Caro O, et al. Response and relapse in patients with schizophrenia treated with olanzapine, risperidone, quetiapine, or haloperidol: 12-month follow-up of the Intercontinental Schizophrenia Outpatient Health Outcomes (IC-SOHO) study. J Clin Psychiatry 2005; 66: 1021-30.

22 Haro JM, Novick D, Suarez D, Alonso J, Lepine JP, Ratcliffe M, et al. Remission and relapse in the outpatient care of schizophrenia. Three-year results from the Schizophrenia Outpatient Health Outcomes Study. J Clin Psychopharmacol 2006; 26: 571-8.

23 Dossenbach M, Pecenak J, Szuic A, Irimia V, Anders M, Logozar-Perkovic D, et al. Long-term antipsychotic monotherapy for schizophrenia: disease burden and comparative outcomes for patients with olanzapine, quetiapine risperidone, or haloperidol monotherapy in a pan-continental observational study. J Clin Psychiatry 2008; 69: 1901-15.

24 American Psychiatric Association. Diagnostic and Statistical Manual of Mental Disorders (4th edn) (DSM-IV). APA, 1994.

25 World Health Organization. The ICD-10 Classification of Mental and Behavioural Disorders: Clinical Descriptions and Diagnostic Guidelines. WHO, 1992.

26 Haro JM, Kamath SA, Ochoa S, Novick D, Rele K, Fargas A, et al. The clinical global impression-schizophrenia scale: a simple instrument to measure the diversity of symptoms present in schizophrenia. Acta Psychiatr Scand 2003; 107 (suppl 416): 16-23.

27 Haro JM, Ochoa S, Gervin M, Mavreas V, Jones P. Assessment of remission in schizophrenia with the CGI and CGI-SCH scales (Letter). Acta Psychiatr Scand 2007; 115: 163-4.

28 Andreasen NC, Carpenter Jr WT, Kane JM, Lasser RA, Marder SR, Weinberger DR. Remission in schizophrenia: proposed criteria and rationale for consensus. Am J Psychiatry 2005; 162: 441-9.

29 Kay SR, Fiszbein A, Opler LA. The positive and negative syndrome scale (PANSS) for schizophrenia. Schizophr Bull 1987; 13: 261-76.
30 Nuechterlein $\mathrm{KH}$, Dawson ME. A heuristic vulnerability/stress model of schizophrenic episodes. Schizophr Bull 1984; 10: 300-12.

31 Grossman LS, Harrow M, Rosen C, Faull R. Sex differences in outcome and recovery from schizophrenia and other psychotic and nonpsychotic disorders. Psychiatr Serv 2006; 57: 844-50.

32 Usall J, Ochoa S, Araya S, Marquez M. Gender differences and outcome in schizophrenia: a 2-year follow-up study in a large community sample. Eur Psychiatry 2003; 18: 282-4.

33 Marshall M, Lewis S, Lockwood A, Drake R, Jones P, Croudace T. Association between duration of untreated psychosis and outcome in cohorts of first-episode patients. Arch Gen Psychiatry 2005; 62: 975-83.

34 Farooq S, Large N, Nielssen $\mathrm{O}$, Waheed W. The relationship between the duration of untreated psychosis and outcome in low- and-middle income countries: a systematic review and meta analysis. Schizophr Res 2009; 109 15-23.

35 Volkow ND. Substance use disorders in schizophrenia - clinical implications of comorbidity. Schizophr Bull 2009; 35: 469-72.

36 Buhler B, Hambrecht M, Loffler W, an der Heiden W, Hafner H. Precipitation and determination of the onset and course of schizophrenia by substance abuse - a retrospective and prospective study of 232 population-based first illness episodes. Schizophr Res 2002; 54: 243-51.

37 Oosthuizen P, Emsley RA, Roberts MC, Turner J, Keyter L, Keyter N, et al. Depressive symptoms at baseline predict fewer negative symptoms at follow-up in patients with first-episode schizophrenia. Schizophr Res 2002; 58: $247-52$.

38 Conley RR, Ascher-Svanum H, Zhu B, Faries DE, Kinon BJ. The burden of depressive symptoms in the long-term treatment of patients with schizophrenia. Schizophr Res 2007; 90: 186-97.

39 Warner R. Recovery from schizophrenia and the recovery model. Curr Opin Psychiatry 2009; 22: 374-80.

40 Marwaha S, Johnson S. Schizophrenia and employment - a review. Soc Psychiatry Psychiatr Epidemiol 2004; 39: 337-49.

41 Thornicroft G, Brohan E, Rose D, Sartorius N, Leese M. Global pattern of experienced and anticipated discrimination against people with schizophrenia: a cross-sectional survey. Lancet 2009; 373: 408-15.

42 Yanos PT, Roe D, Markus K, Lysaker PH. Pathways between internalized stigma and outcomes related to recovery in schizophrenia spectrum disorders. Psychiatr Serv 2008; 59: 1437-42. 